\title{
Perception of distance learning in Bangladeshi tertiary education: prospects and obstacles in the Covid-19 era
}

\author{
S. M. Sabbih Hossain ${ }^{1}$, Md. Rahat Khan ${ }^{2 *}$
}

Assistant Professor, Department of English, City University, Dhaka, Bangladesh ${ }^{1}$

Assistant Professor, Department of Business Administration, City University, Dhaka, Bangladesh ${ }^{2 *}$ sabbih.hossain@gmail.com ${ }^{1}$, rahat.khan.dba@ @ityuniversity.edu.bd ${ }^{2 *}$

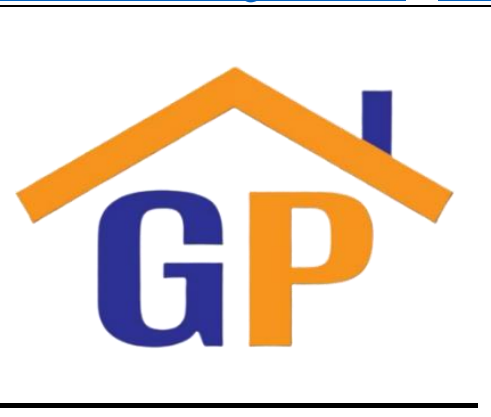

Article History

Received on 14 April 2021

Revised on 30 April 2021

Accepted on 5 May 2021

\begin{abstract}
Purpose: The key purpose of the study is to understand the university students' perception of a sudden distance learning platform from Bangladesh (a least developed countries' perspective).
\end{abstract}

Research methodology: This particular study has employed a qualitative research method with the support of interview and observation methods. The study has selected 20 University students as a sample size based on purposive sampling.

Results: The findings provide a vivid outline of the current situation of the universities- that the students have- over the influence of distance learning on education, technology, their university, course instructors, and themselves.

Limitations: The data was qualitative in nature and the study only interviewed the university students but not the other stakeholders of that system; in addition, the study did not triangulate the data with more quantitative data.

Contribution: The study makes an important contribution to the literature on the least developed countries' university education, which will benefit Higher Education institutions that are also struggling with the prospects and obstacles of distance learning during and in the post-Covid-19 crisis

Keywords: University students' perception, Distance learning, Covid-19

How to cite: Hossain, S. M. S., \& Khan, M. R. (2021). Perception of distance learning in Bangladeshi tertiary education: prospects and obstacles in the Covid-19 era. Journal of Social, Humanity, and Education, 1(3), 197-207.

\section{Introduction}

The significance of distance learning is recognised worldwide. Many countries have adopted this distance learning platform for higher education and staff development purposes (Saunders et al., 2019; Cacault \& Laurent-Lucchetti, 2020). The perceptual factors have been explored and measured in many studies to unearth the real targeted outcomes (Khan et al., 2019; Daroedono et al., 2020; Khan \& Sharma, 2020; Giovannella, 2021). In the case of Bangladesh, this distance learning platform is not entirely new, but it was not widely accepted before the Covid-19 crisis. Few universities had their own distance learning management system before this pandemic (Islam \& Selim, 2006), but to a very low extent. Hence, this Covid-19 crisis sends the policymakers of Bangladeshi higher education institutions (HEIs) to rethink about online-based education along with distance learning platforms (British Council Bangladesh, 2020). Due to the current unforeseen Covid-19 pandemic, the pedagogical system has taken a new turn; as in almost all the countries, direct or indirect lock-down is going on. So, at the moment, distance learning is not any more optional or is not limited to any particular group of learners; rather, it has become a precondition for most of the educational 
institutions (including primary, secondary, universities) if they are to continue the flow of the teaching-learning process. As part of the global efforts to combat Covid-19, many countries across the world closed down schools in an attempt to contain the coronavirus pandemic. According to the United Nations Educational, Scientific and Cultural Organization (UNESCO) monitoring, over 100 countries implemented nationwide closures, impacting over half of the world's student population (VOA News, 2020).

However, much of the academic literature focuses on the impact of distance learning on students and the plethora of technologies that support its delivery (Isaias et al., 2017; Holmes et al., 2019; Law, Geng, \& Li, 2019). Only a minority of studies directly consider the impact of transitioning to distance learning on academic and support staff, and the focus of these studies is typically on a narrow aspect such as staff workload (Tynan et al., 2015; Saunders et al., 2019); Technology acceptance (Wingo et al., 2017; Alshurideh et al., 2019; Handoko, 2019); Engineering Education (Kinney et al., 2012; Saunders et al., 2019) etc. Few studies can be found on distance learning platform for the least developed countries (LDCs) (Andersson \& Grönlund, 2009; Bhuasiri et al., 2012; Valencia-Arias et al., 2019); however, there is no such specific research found based on the sudden distance learning perception of university students; more specifically for LDCs perspective. The increasing use of technology in education has modified teachers' methods from the traditional approach that often place them as dispensers of knowledge to a more flexible approach where they act more as facilitators, mentors and motivators to inspire students to participate and learn (Onyema et al., 2019). Most aspects of education are going digital, and education stakeholders, including students, are confronted with the challenge of transition to online education. The use of appropriate educational technologies increases accessibility to learning resources such as Massive Open Online Courses (MOOCs) and multiple learning approaches to meet diverse learners' needs (Onyema, Ogechukwu \& Anthonia, 2019).

Many works looking at the broader perspective of stakeholders involved in distance learning have been done (Mansbach \& Austin, 2018; Zheng et al., 2019), but still 'significant gaps in the current research' concerning the role of the instructors and learners can be found (Siemens, Gašević, \& Dawson 2015; Martin et al., 2019). If we are to examine the broader perception of university students towards engaging in distance learning education, this is significantly true, especially in terms of the personal development opportunities that it provides. This study makes an important contribution to the literature on distance learning by focusing specifically on the real-time challenges facing university students when tasked with developing new distance learning procedures from previously existing campus-based ones before the Covid-19 crisis. This qualitative study has been carried out within the university students' perception on a sudden distance learning platform from Bangladesh (a LDC perspective). Data has been collected from structured interviews with university students (undergrad and graduate) engaged in the newly established distance learning platform during this Covid-19 crisis. The main research questions have been set as:

RQ-1. What are students' attitudes and perceptions towards the sudden distance learning system in the universities during the Covid-19 crisis?

RQ-2. What could be the prospects and obstacles of the current distance learning platform during and in the post-Covid-19 period?

The strategy of operations may vary based on the environmental context (Khan et al., 2018). By answering these questions, the study provides UGC and the universities of Bangladesh with the knowledge to better understand students' perception towards distance learning, enabling UGC and the universities to foster the right environment for academic and instructional design teams to develop and deliver effective distance learning programmes during Covid-19 crisis.

This is the primary contribution of this paper. This paper has been designed as follows; the upcoming section narrates the Bangladeshi distance learning platform before and during the Covid-19 crisis, the impact of the Covid-19 crisis on the Bangladeshi education system, and related research on distance learning platform, and suitable distance learning platform from LDCs context. The third section 2021 | Journal of Social, Humanity, and Education/ Vol 1 No 3, 197-207 
describes the methods of this research. The subsequent sections describe the results and analysis, discussion, conclusion, limitations, future research, academics and policymakers, and implications of this research.

\section{Literature review}

\subsection{Covid-19 and its impact on the Bangladeshi education system}

The economic uneasiness during the outbreak of the Covid-19 is mostly but not completely limited to the tension of health systems of being unable to deal with more routine health issues during outbreaks (Khan, 2020); costs of medical treatment of the infected and outbreak control, costs of the health system as a whole, both public and private; loss of employee productivity, of educational institutions; destabilisation on the tourism section and so on (Goodell, 2020). The pedagogical framework has taken a new turn in Bangladesh, owing to the latest unexpected Covid-19 pandemic. Hence, distance learning is no longer optional at the moment or is not restricted to any specific community of learners; instead, it has become a precondition for most Bangladesh educational institutions to continue the flow of the teaching-learning stream (Ilmiyah \& Setiawan, 2020). There is always a chance that some faculty members who are not techno-savvy will not be able to cope with this mode. The transition to online mode has raised questions for the faculty about their capability to deal with the existing technology (Lee, 2020). In Bangladesh, the scenario is also the same; as of April 29, 2020, 63 universities started teaching online classes out of 133 universities (including private and public universities). The number is increasing rapidly (mainly in private universities). However, a clear division is seen among the academicians and public universities regarding the outcome of the online classes and, thus, learning. Even, University Grants Commission of Bangladesh conducted an online survey on the effectiveness of online higher education over the past two months (April and May of 2020), to formulate an Online Education Learning Policy for the current situation as well as the future and the findings suggested, Bangladeshi educational institutions need to do a lot more in order to be ready for conducting online classes (Dhaka Tribune, 2020). But still, every day, the number of universities conducting online classes is increasing.

\subsection{Probable framework suitable for Bangladeshi context}

The transition to online learning from a classroom-based learning system closely connects to the relationship between costs and benefits. However, the particulars of this will vary for each key stakeholder (e.g. students, teaching staff, support staff, the hiring industry, and the higher educational institution itself) (Wagner et al., 2008). It is challenging to determine and it requires extensive research on it. A lot of works have been done on cost-benefit analyses in online learning (for example, Xia, 2015; Legon \& Garrett 2018; Harrison, 2019), but Laurillard's study reveals that the costing models have almost no impact on practical activities in educational institutions' planning e-learning innovation (Laurillard 2007). They lack consistency and do not fit existing practices. They require a good amount of effort on user's and innovator's part to work out costs normally unavailable to them, especially for the recondite nature of teaching costs. This is particularly relevant as the techniques, technologies, mobile phone networks, partnership opportunities, competitors, demographics, and delivery models involved in distance learning initiatives are evolving rapidly (Saunders et al., 2019; Khan et al., 2021). Moreover, the impact and influence can vary as the perceived benefits and disadvantages of distance learning are varied. Betts \& Heaston (2014) conducted a survey that weighed the perspectives of academic staff and deans against a list of 29 motivating and 20 inhibiting factors- we see that faculty with distance education experience consider the vital motivating factors quite differently to those without the experience. An important but unsurprising finding from this research is that experienced participants said the key role is played by personal motivation. The main inhibitors were more similar between the groups, with these fitting into three main areas: quality, time and support. 


\section{Research methodology}

This particular study has employed a qualitative research method with the support of interview and observation method. Hence the study has designed a suitable interview schedule before discussing it with the participants. As the research area is affected by the Covid-19 pandemic, thus physical interviewing was not appropriate for the health concern of both the interviewer and the interviewees. For those consequences, the study arranged some online interviews over a Zoom meeting (online meeting platform) after getting prior mutual consent from each participant. The interview was conducted from June 25 to July 10 of this year, 2020. The interview questions began with some demographic information and some relevant questions that are fully consistent with the aim of this research. All the questions were threatening, non-sensitive, easy to answer, and entirely focused on this research, as suggested by (Polit et al., 2004; Trochim, 2005). The duration of each interview session was 15 to 30 minutes (Daley et al., 2019) according to the response and convenience of the interviewees. For this particular study, interviewers asked interviewees precisely the identical formatted sequence of questions. Thus, the study picked up a structured method of interviewing for data collection as recommended by (Ryan et al., 2009). The study population is the students from different Universities in Bangladesh who are experiencing the sudden distance learning management system during this Covid-19 crisis. Only 63 universities out of 133 universities have started teaching online classes (Dhaka Tribune, 2020). Hence the study population size of the study is lying among the 63 Universities' students. There is a lack of exact data about the total population size. According to Latham (2020), for interview and observation analysis, 15 to 20 interviewers are well enough to conduct a qualitative study. Latham (2013) suggests that overload sometimes takes place in homogeneous communities of about 12 members. Therefore, a minimum of 15 respondents works very well if they are homogenous for the most qualitative research (Latham, 2020). To avoid saturation, 15 to 20 respondents, as a minimum, fit quite well because the subjects are homogenous with qualitative interview methods (Crouch \& McKenzie, 2006). Thus a 20 number of University students are considered as sample size based on purposive sampling technique (Lavrakas, 2008). After collecting the data, the study has been arranged data through a judgment approach and the arranging data have been presented in the narrative way (Khan, 2019; Khan \& Sharma, 2020).

\section{Results and analysis}

\subsection{Interview participants profile}

The study selected $(N=20)$ students from the 63 universities who are going through the distance learning system in Bangladesh.

Table 1. Summary of respondents profile

\begin{tabular}{|c|c|c|c|}
\hline Name (*) & Gender & Age & University \\
\hline S-1 & Male & 21 to 25 Years & Army IBA, Savar (Bangladesh University of Professionals \\
\hline $\mathrm{S}-2$ & Male & 21 to 25 Years & Army IBA, Savar (Bangladesh University of Professionals \\
\hline S-3 & Female & 21 to 25 Years & BRAC University, Bangladesh \\
\hline S-4 & Male & 21 to 25 Years & BRAC University, Bangladesh \\
\hline S-5 & Female & 21 to 25 Years & City University, Bangladesh \\
\hline S-6 & Male & 21 to 25 Years & City University, Bangladesh \\
\hline S-7 & Male & 26 to 30 years & East Delta University, Bangladesh \\
\hline $\mathrm{S}-8$ & Female & 21 to 25 Years & East Delta University, Bangladesh \\
\hline S-9 & Female & 21 to 25 Years & USTC medical college, Bangladesh \\
\hline$S-10$ & Male & 21 to 25 Years & USTC medical college, Bangladesh \\
\hline S-11 & Male & 21 to 25 Years & Shahjalal University of Science and Technology, Bangladesh \\
\hline S-12 & Female & 21 to 25 Years & Shahjalal University of Science and Technology, Bangladesh \\
\hline S-13 & Female & 26 to 30 years & University of Liberal Arts, Bangladesh \\
\hline S-14 & Male & 21 to 25 Years & University of Liberal Arts, Bangladesh \\
\hline S-15 & Male & 21 to 25 Years & North South University, Bangladesh \\
\hline$S-16$ & Female & 21 to 25 Years & North South University, Bangladesh \\
\hline S-17 & Male & 26 to 30 years & Daffodil International University, Bangladesh \\
\hline S-18 & Female & 21 to 25 Years & Daffodil International University, Bangladesh \\
\hline S-19 & Male & 21 to 25 Years & Jahangirnagar University, Bangladesh \\
\hline
\end{tabular}


From table 1, among the interview participants, this study found two participants from Army IBA, Savar (Bangladesh University of Professionals); two interview participants from BRAC University, two interview participants from City University, two interview participants from East Delta University, two interview participants from USTC medical college, two interview participants from Shahjalal University of Science and Technology, two interview participants from University of Liberal Arts, two interview participants from North South University, two interview participants from Daffodil International University, two interview participants from Jahangirnagar University. The age range of the participants has observed as between 21 to 25 years are seventeen interview participants and the rest of the three interview participants lie between 26 to 30 years. From all the interview participants, nine are found as female, while eleven are found as male respondents. It has also found from the table-1 that sixteen interview participants are enrolling at undergrad study and four interview participants are enrolling at Master level study in their respective Universities.

\title{
4.2. Perception on adaptation towards current distance learning
}

All the students were asked about their perception of adaptation towards distance learning. A mixed opinion has been observed from the discussion answers. A portion of the participants who are experiencing this distance learning platform shared their positive view of adaptation, while others shared criticisms regarding the current distance learning system. Due to privacy reasons, the study cannot reveal the participants' name and their affiliated University. Hence the analyses use coding words to describe the responses. The below quotation $((Q-1)$ from a student indicates several students' responses who share their positive perception of distance learning.

Q-1. I am personally adapting quite well. I would rather stay home for safety and continue my education during this pandemic than do nothing for days or go outside unwillingly. I have WiFi at home; therefore, it is not really a problem to attend online classes for me unless the electricity goes away. My institution has also made it as easy as they could for all of us on such short notice. There were a few hurdles at first, but I believe they will only keep improving and things will run very smoothly from now on.

Though the students were constructive but at the same time, they shared some criticisms towards this current distance learning system. The below two quotations ( $Q-2$ and $Q-3)$ from two students indicate several students' responses who shared similar criticism.

\begin{abstract}
Q-2. The university activities such as classes, assignments, quizzes are taken through online due to Covid19.As we had no experience for all of these; it is taking time to adapt with this situation. Distance learning may be good for saving time, energy but direct participation is more beneficial for me. Being a finance student I must solve mathematical problems. But due to the slow speed of internet connection, it is quite difficult to understand when the class is conducted by the respective teachers.
\end{abstract}

Q-3. I have troubles adjusting to it, because I don't have a laptop, so I have to do all the works on the phone. No internet data pack, weak network, phone runs out of charge, so I can't do the next class if I attend in one class. Honestly, I like to sit at home and take classes, but I can't find real education which I get from attending class myself. However, keeping in mind the situation of the country, I have adapted a lot now.

Some significant perceptual factors have been observed from the above analysis. First, the students who can afford modernised learning devices such as their own tablet, PC, high internet connectivity, and having good knowledge of IT-based learning management systems can easily adapt to the platform. While the second one, the students who are also able to afford learning devices such as laptop, PC, high internet connectivity and having good knowledge of IT but attend in mathematical or laboratory-based classes are facing troubles while adaptation, and the final one, the students who are unable to afford modernised learning devices and supports such as personal computer, high internet connectivity and having poor knowledge of IT-based learning management system are also facing huge difficulties in adaptation. 


\title{
4.3. Perception on course instructors' effectiveness and adaptability in current distance learning
}

This section tries to reveal students' perception of course instructors' effectiveness and adaptability in the current distance learning system. Most of the students share their positivity towards instructors' willingness to teach them well; however, few criticisms have also been exposed from the participants. The three students' below three quotations ((Q-4, Q-5, and Q-6) indicate several students' responses who share their positive perception of course instructors' effectiveness and adaptability.

\begin{abstract}
Q-4. I believe our course instructors are doing their absolute best to adapt and cope up with such a situation never seen before and are putting all their efforts into making it is easy for all the students to be able to continue their studies. I have nothing but gratitude and respect for them and would like to encourage them to keep up the excellent work. They have all been understanding and supportive and I am extremely appreciative of everything they have and are doing for their students. I want to thank them for their patience and selflessness.
\end{abstract}

Q-5.I heard from one of my University faculty members that he was preparing for this online semester from mid-May, whereas classes started on July 01. Now, they are very effective in this new system.

Q-6. This distance learning system, or if I say the online-based class is a very new experience for both the teachers and the students, teachers are also going through some new experiences, Now they adapted the system very strongly, and their classes and lectures are very effective for us They are able to make us understand the lessons very easily, Their leaching ability is as it was before Now, they work more than before for us. They have taken these difficulties very professionally.

On the other hand, few constructive criticisms are observed from the respondents' responses as well. The below three quotations $(Q-7, Q-8$ and $Q-9)$ from the students indicate constructive criticism on course instructors' effectiveness and adaptability.

Q-7. I think the Distance Learning System is the real-life classroom experience through an online platform. If so, I can't give my course instructors, ability to adapt to 100 out of 100; If I do the marking, I can give 50 or 60 out of 100.

Q-8.Distance learning is a considerably new term for both the students and the instructors. They used to take classes in front of a gathering of students where students could directly participate, and the teachers could monitor us. At this time, when instructors are taking classes sometimes, they don't understand whether the students understand the lessons properly or not, especially when they solve mathematics, cases, theories online. It needs time to adapt to the situation effectively.

Q-9. Almost all of them have adapted to the new model. As our Zoom (meeting platform) is time-limited to 40 minutes only, it breaks the rhythm of a lecture delivered for some course instructors. So, in that case, the premium version can be adapted. If the video is kept on for everyone, then I think teachers will enjoy teaching to an extent the way they do in class.

Based on the above analysis, it can be said students are positive regarding the course instructors' effectiveness and adaptability in current distance learning; however, few of them believe proper training and logistics support for their course instructors are obvious for better adaptability.

\subsection{Students' perception regarding the opportunities and challenges in distance learning}

The respondents are very much concerned about the opportunities and challenges in distance learning. All of them shared their opinions on the ground of this discussion point. The below three quotations $((Q-10, Q-11$, and $Q-12)$ from the students can summarise the whole responses which are sharing their perception regarding the opportunities and challenges in distance learning.

Q-10. Where some universities have not started distance learning system activities, we are far ahead as our universities started these activities earlier. In addition, Our university has shown sympathy where other universities have forced students to take classes in distance learning systems. It has encouraged us in the distance learning system by emphasising its importance rather than forcing it.

Q-11. I think it is a better system for learning. Students are now learning through information systems. The students having no knowledge about IT systems are now also adapting to this system. Now we know how to send pictures through e-mail effectively. Now we know how to use Google classroom etc. So, I think this 
system is really beneficial for all the students. Already, many universities adopted this system in their education system. They used to give the class notes, assignment through the IT system before the COVID-19 era. So I think it's a big challenge for us to cope up with this system. Because many students still don't know how to use this system, so it's definitely challenging for us.

\begin{abstract}
Q-12. We are using zoom, Google meet, Google classroom apps/websites for participating in the classes. These apps are very easy and helpful to continue the classes. We are participating in our online classes regularly and the semester is going on. We don't sit idly, rather keep us busy with our classes, assignments like before. However, some of the students who are outside of Dhaka City are facing problems. They have to spend their money to buy internet packages and sometimes they can't participate in the classes due to poor connection of internet network. The semester fee is the most challenging thing at this time. We do not have any scopeloffer to provide a minimum semester fee during this pandemic situation.
\end{abstract}

Based on the discussion, some opportunities and key challenges are revealed from the participants who are engaging in real-life experiences on distance learning. The probable opportunities are 1) students and teachers are trying to adopt this new platform; 2) broadening their IT knowledge; 3) overcoming the session jam barriers. On the other hand, the possible challenges are observed as, 1) still many of the universities are not launching their distance learning platform; hence those students may face huge session jam; 2) students from remote areas are in trouble to adapt this distance learning platform due to poor network and IT facilities; 3) identical distance learning platform for all universities cannot be ensured.

\title{
4.5. Students' proposals to make this current distance learning platform more effective
}

In this section, the interviewees were also asked to share some proposals to make this current system more interactive and effective for learning. Based on their comments, the following proposals can be pointed out.

P 1) UGC or the Universities (policymakers) of a least developing country like Bangladesh need to support free or reasonable packages of the internet to the students for furthering the instructiveness and effectiveness of distance learning systems.

P 2) Policymakers need to build funding for financial aid to those students who cannot afford modernised IT-based learning devices such as laptops, tablets etc.

P 3)Policymakers need to create more awareness and supportive programs for developing a positive mental set up towards distance learning systems.

P 4) University authorities have to make their own exam portal using a) WAMP Server, $b$ ) XAMPP Server, c) MAMP Server d) LAMP Server.

P 5) Both teacher and student have to be trained about online class/exam method, e.g. Zoom, Google Meet, Google classroom etc.

P 6) Both the recorded classes and the live classes can be more effective in distance learning

\subsection{Discussion}

Based on the above analysis, this study concludes that all the participants have mixed opinions regarding this sudden platform of distance learning education in Bangladesh. However, both parties have some strong logic in their comments. In this particular section, the study has tried to compare the result with previous works of literature. As the study has separated its analysis with three specific perception criteria, the study outcomes need a comparison with each perception criterion. The following table shows the comparisons with previous works of literature. The outcomes of this study regarding perception on adaptation with the distance learning systems have supported the study of (Sherry, 1995; Schweisfurth, 2011; Saunders et al., 2019); and the new contribution from this section is the mathematical or laboratory-based practical classes are tough to adapt and distance learning platform is better adaptable for introvert students. In another perception related outcomes regarding course, instructors' effectiveness and adaptability in current distance learning supported the study of Stevenson et al. (1996); Inman (1999); MacDonald (2008); Shah et al. (2015); Law et al. (2019); and the new contribution from this section is the variation of instructor's age has a great impact on the adaptability of distance learning. In addition, an outcome towards students' perception regarding the prospects and obstacles in distance learning has supported the study of Pena-Bandalaria (2007); 2021 | Journal of Social, Humanity, and Education/ Vol 1 No 3, 197-207 
Wagner et al. (2008); Ma \& Lee (2019); and the new contribution from this section is: the pandemic situation is heading towards digitalised higher education as a part of country's vision and an identical distance learning platform needs to be ensured. Based on the analysis and discussion, this current study can easily meet the answer to both the research questions.

\section{Conclusion, implications, and future research}

This study makes two significant contributions to theory and practice. Firstly, the findings provide a rich picture of the prospects and obstacles from the students' point of view and their perception on adaptation, perception on course instructors' effectiveness and adaptability, perception regarding the prospects and obstacles towards current distance learning. In doing so, the study makes an essential contribution to the literature on LDCs university education, which will benefit HE institutions around the LDCs who are also struggling with the prospects and obstacles of distance learning during and in the post-Covid-19 crisis. The real-time experiences of the participants in this study exemplify the perception of distance learning on educational approaches adopted by universities and UGC Bangladesh and the Covid-19 impact on their already existing education system. The participants in this study viewed distance learning as offering opportunities for learners to cope with new systems and learn new technologies; folding back new content into the existing programmes and simultaneously transforming existing programmes and units into a more advanced learning style. Stakeholders also grasped the benefits of distance learning- for the institution, it matters in terms of increased reputation and for students, it matters from the perspective of adaptability and avoiding the session jam. Secondly, the study produces prior literature and the outcomes of the research to proffer a number of recommendations for stakeholders to consider required for a practical distance learning education. Interrogating students' impression about distance learning in this particular way and coming up with insights into the support system that universities and UCG need in order to develop and deliver high quality and effective distance learning programmes and all should enhance the opportunities and minimise the barriers to a successful roll-out of distance learning.

There have some lots of corridor to run for future research based on the outcomes of this study. The data was qualitative in nature and the study only interviewed the university students but not the other stakeholders of that system; in addition, the study did not triangulate the data with more quantitative data such as online-based distance learning versus campus-based teaching. Secondly, the collected data in this research provides only a snapshot of students' perception, based on structured interviews. A further study, which may interview the other stakeholders on distance learning, would provide further insights into the current distance learning system. Lastly, this study related works were conducted in a single least developed country like Bangladesh. Replicating the study across other LDCs would most likely provide a further understanding of distance learning's students' perceptions.

\section{References}

Alshurideh, M., Al Kurdi, B., \& Salloum, S. A. (2019, October). Examining the main mobile learning system drivers' effects: A mix empirical examination of both the Expectation-Confirmation Model (ECM) and the Technology Acceptance Model (TAM). In International Conference on Advanced Intelligent Systems and Informatics (pp. 406-417). Springer, Cham.

Andersson, A., \& Grönlund, Å. (2009). A conceptual framework for e-learning in developing countries: A critical review of research challenges. The electronic Journal of information systems in developing Countries, 38(1), 1-16.

Betts, K., \& Heaston, A. (2014). Build it but will they teach?: Strategies for increasing faculty participation \& retention in online \& blended education. Online Journal of Distance Learning Administration, 17(2), n2.

Bhuasiri, W., Xaymoungkhoun, O., Zo, H., Rho, J. J., \& Ciganek, A. P. (2012). Critical success factors for e-learning in developing countries: A comparative analysis between ICT experts and faculty. Computers \& Education, 58(2), 843-855.

British Council Bangladesh. (2020). Continuing academic activities online in higher education institutions. Retrieved from, https://www.britishcouncil.org.bd/en/continuing-academicactivities-online-higher-education-institutions. 
Cacault, H., \& Laurent-Lucchetti, P. (2020). Distance learning in higher education. Depression.

Crouch, M., \& McKenzie, H. (2006). The logic of small samples in interview-based qualitative research. Social science information, 45(4), 483-499.

Daley, C., Cornet, V., Patekar, G., Kosarabe, S., Bolchini, D., Toscos, T., \& Ahmed, R. (2019, September). Uncertainty Management Among Older Adults with Heart Failure: Responses to Receiving Implanted Device Data using a Fictitious Scenario Interview Method. In Proceedings of the International Symposium on Human Factors and Ergonomics in Health Care (Vol. 8, No. 1, pp. 127-130). Sage CA: Los Angeles, CA: SAGE Publications.

Daroedono, E., Siagian, F. E., Alfarabi, M., Cing, J. M., Arodes, E. S., Sirait, R. H., ... \& Hutabarat, R. S. (2020). The impact of Covid-19 on medical education: our students perception on the practice of long distance learning. International Journal of Community Medicine and Public Health, 7(7), 2790-2796.

Dhaka Tribune. (2020). Coronavirus: 63 universities taking online classes across Bangladesh. retrieved from, https://www.dhakatribune.com/health/coronavirus/2020/04/29/coronavirus63-universities-taking-online-classes-across-bangladesh.

Giovannella, C. (2021). Effect induced by the Covid-19 pandemic on students' perception about technologies and distance learning. In Ludic, Co-design and Tools Supporting Smart Learning Ecosystems and Smart Education (pp. 105-116). Springer, Singapore.

Goodell, J. W. (2020). Covid-19 and finance: Agendas for future research. Finance Research Letters, 101512 .

Handoko, B. L. (2019). Technology Acceptance Model in Higher Education Online Business. Journal of Entrepreneurship Education, 22(5), 1-9.

Harrison, M., Quisias, J., Frew, E. J., \& Albon, S. P. (2019). A Cost-Benefit Analysis of Teaching and Learning Technology in a Faculty of Pharmaceutical Sciences. American Journal of Pharmaceutical Education, 83(6).

Holmes, W., Nguyen, Q., Zhang, J., Mavrikis, M., \& Rienties, B. (2019). Learning analytics for learning design in online distance learning. Distance Education, 40(3), 309-329.

Ilmiyah, S., \& Setiawan, A. R. (2020). Students' Worksheet for Distance Learning Based on Scientific Literacy in the Topic Coronavirus Disease 2019 (Covid-19).

Inman, E., Kerwin, M., \& Mayes, L. (1999). Instructor and student attitudes toward distance learning. Community College Journal of Research \& Practice, 23(6), 581-591.

Isaias, P., Reis, F., Coutinho, C., \& Lencastre, J. A. (2017). Empathic technologies for distance/mobile learning. Interactive Technology and Smart Education. Vol. 14 No. 2, pp. 159-180.

Islam, M. T., \& Selim, A. S. M. (2006). Current status and prospects for e-learning in the promotion of distance education in Bangladesh. Turkish Online Journal of Distance Education, 7(1).

Khan, M. R. (2019). Samson H. Chowdhury: a true entrepreneurial leader for Square Group. EuroMed Journal of Management, 3(2), 80-88.

Khan, M. R. (2020). Ethical business practice and short term earning intensity during the Covid-19 crisis in Bangladesh. International Journal of Financial, Accounting, and Management, 2(2), 79-93.

Khan, M. R., \& Sharma, K. (2020). Purchase Preferences and Buying Influences on Religious Occasions. FIIB Business Review, 9(3), 216-227.

Khan, M. R., Hossain, S. K., \& Rabbi, M. M. I. (2018). The Strategic Environment Analysis of Islami Bank Bangladesh Limited (IBBL). IIUM Journal of Case Studies in Management, 9(1), 2841.

Khan, M. R., Rana, S., \& Hosen, M. I. (2021). Impact of Trustworthiness on the Usage of M-banking Apps: A Study on Bangladeshi Consumers. Business Perspectives and Research, 22785337211001969.

Khan, M. R., Roy, S. K., \& Hossain, S. M. (2019). FACTORS AFFECTING GARMENTS EMPLOYEES'PERCEPTION ON JOB PERFORMANCE: EVIDENCE FROM BANGLADESH. International Journal of Management and Sustainability, 8(1), 32-47. 
Kinney, L., Liu, M., \& Thornton, M. A. (2012). Faculty and student perceptions of online learning in engineering education. In American Society for Engineering Education. American Society for Engineering Education.

Latham, J. R. (2013). A framework for leading the transformation to performance excellence part I: CEO perspectives on forces, facilitators, and strategic leadership systems. Quality Management Journal, 20(2), 12-33.

Latham, J. R. (2020). Qualitative Sample Size - How Many Participants is Enough? Retrieved from, https://www.drjohnlatham.com/many-participants-enough/.

Laurillard, D. (2007). Modelling benefits-oriented costs for technology enhanced learning. Higher Education, 54(1), 21-39.

Lavrakas, P. J. (2008). Purposive sample. Encyclopedia of Survey Research Methods, 2455.

Law, K. M., Geng, S., \& Li, T. (2019). Student enrollment, motivation and learning performance in a blended learning environment: The mediating effects of social, teaching, and cognitive presence. Computers \& Education, 136, 1-12.

Lee, K. (2020). Coronavirus: universities are shifting classes online - but it's not as easy as it sounds. Retrieved from, https://world.edu/coronavirus-universities-are-shifting-classes-online-but-itsnot-as-easy-as-it-sounds/.

Legon, R., \& Garrett, R. (2018). The changing landscape of online education (CHLOE) 2: A deeper dive. Quality Matters \& Eduventures Survey of Chief Online Officers.

Ma, L., \& Lee, C. S. (2019). Understanding the barriers to the use of MOOCs in a developing country: An innovation resistance perspective. Journal of Educational Computing Research, 57(3), 571-590.

MacDonald, J. (2008). Blended learning and online tutoring: Planning learner support and activity design. Gower Publishing, Ltd.

Mansbach, J., \& Austin, A. E. (2018). Nuanced perspectives about online teaching: Mid-career and senior faculty voices reflecting on academic work in the digital age. Innovative higher education, 43(4), 257-272.

Martin, F., Budhrani, K., Kumar, S., \& Ritzhaupt, A. (2019). Award-winning faculty online teaching practices: Roles and competencies. Online Learning, 23(1), 184-205.

Onyema, E. M., Deborah, E. C., Alsayed, A. O., Noorulhasan, Q., \& Naveed, S. S. (2019). Online Discussion Forum as a Tool for Interactive Learning and Communication. International Journal of Recent Technology and Engineering, 8(4), 4852-4859.

Onyema, E. M., Ogechukwu, U., \& Anthonia, E. C. D. (2019). Potentials of Mobile Technologies in Enhancing the Effectiveness of Inquiry-based Learning Approach. International Journal of Education (IJE), 2(01).

Pena-Bandalaria, M. (2007). Impact of ICTs on open and distance learning in a developing country setting: The Philippine experience. International Review of Research in Open and Distance Learning, 8(1), 1-15.

Polit, D. F., Beck, C. T., \& Hungler, B. P. (2004). Lehrbuch Pflegeforschung. Huber.

Ryan, F., Coughlan, M., \& Cronin, P. (2009). Interviewing in qualitative research: The one-to-one interview. International Journal of Therapy and Rehabilitation, 16(6), 309-314.

Saunders, F. C., Brooks, J., \& Dawson, M. (2019). Exploring staff attitudes to distance learning-what are the opportunities, challenges and impacts on engineering academics and instructional designers. European Journal of Engineering Education, 1-16.

Schweisfurth, M. (2011). Learner-centred education in developing country contexts: From solution to problem?. International Journal of Educational Development, 31(5), 425-432.

Shah, S., Bellows, B. A., Adedipe, A. A., Totten, J. E., Backlund, B. H., \& Sajed, D. (2015). Perceived barriers in the use of ultrasound in developing countries. Critical ultrasound journal, 7(1), 1-5.

Sherry, L. (1995). Issues in distance learning. International journal of educational telecommunications, 1(4), 337-365.

Siemens, G., Gašević, D., \& Dawson, S. (2015). Preparing for the digital university: A review of the history and current state of distance, blended, and online learning. Retrieved from, 
https://www.igi-global.com/chapter/digital-library-and-distance-learning-in-developingcountries/232432, DOI: 10.4018/978-1-5225-8437-7.ch011.1=

Stevenson, K., Sander, P., \& Naylor, P. (1996). Student perceptions of the tutor's role in distance learning. Open Learning: The Journal of Open, Distance and e-Learning, 11(1), 22-30.

Trochim, W. M. (2005). Research methods: The concise knowledge base. Atomic Dog Publishing.

Tynan, B., Ryan, Y., \& Lamont-Mills, A. (2015). Examining workload models in online and blended teaching. British Journal of Educational Technology, 46(1), 5-15.

Valencia-Arias, A., Chalela-Naffah, S., \& Bermúdez-Hernández, J. (2019). A proposed model of elearning tools acceptance among university students in developing countries. Education and Information Technologies, 24(2), 1057-1071.

VOA News. (2020). UNESCO: 290 Million Students Stay Home due to Coronavirus. Retrieved from, https://learningenglish.voanews.com/a/unesco-290-million-students-stay-home-due-to coronavirus/5317148.html.

Wagner, N., Hassanein, K., \& Head, M. (2008). Who is responsible for e-learning success in higher education? A stakeholders' analysis. Journal of Educational Technology \& Society, 11(3), 2636.

Wingo, N. P., Ivankova, N. V., \& Moss, J. A. (2017). Faculty perceptions about teaching online: Exploring the literature using the technology acceptance model as an organising framework. Online Learning, 21(1), 15-35.

Xia, B. S. (2015). Benefit and cost analysis of massive open online courses: Pedagogical implications on higher education. International Journal of Cyber Behavior, Psychology and Learning (IJCBPL), 5(3), 47-55.

Zheng, Y., Ghane, N., \& Sabouri, M. (2019, June). Personalised educational learning with multistakeholder optimisations. In Adjunct Publication of the 27th Conference on User Modeling, Adaptation and Personalisation (pp. 283-289). 